
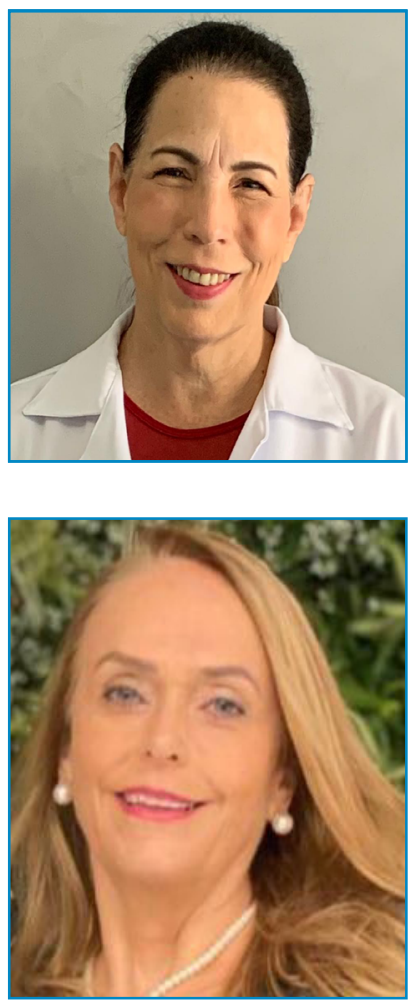

\title{
SEGUINDO OS PASSOS DE NORMA GILL
}

\section{FOLLOWING NORMA GILL'S FOOTSTEPS}

\section{SIGUIENDO LOS PASOS DE NORMA GILL}

\section{Isabel Cristina Ramos Vieira Santos ${ }^{1, \star(D)}$, Maria Angela Boccara de Paula² (D)}

Em junho, temos o privilégio de honrar Norma N. Gill-Thompson, relembrando seus feitos. Essa senhora, enquanto jovem, numa época de poucos recursos tecnológicos quando comparada aos dias de hoje, foi acometida por colite ulcerativa que resultou na realização de uma cirurgia com a confecção de uma ileostomia terminal.

Como tantas outras pessoas que vivenciam essa situação, ela poderia ter se deixado levar pelas dificuldades, comprometendo seu modo de vida, mas ao invés disso, viu oportunidade para não apenas melhorar sua própria condição, como a de muitas outras pessoas com estomias. Fazendo valer o dito "a necessidade é a mãe da invenção"1. A preocupação de viver com uma estomia a motivou a reunir elementos para que os cuidados pudessem ser efetivos e adequados às demandas de uma pessoa com estomia.

Trabalhando juntamente com o cirurgião Rupert B. Turnbull Jr., médico que a operou, participou ativamente do processo de reabilitação de pessoas com estomias e fístulas, e contribuiu para o desenvolvimento de equipamentos coletores mais eficazes e eficientes que, de certo, levou à importante melhoria da qualidade de vida dessas pessoas. Na base dos cuidados elaborados por Norma N. Gill-Thompson estão os requisitos necessários à sua realização, quais sejam: competência clínica, habilidade educacional, interesse científico e proteção do paciente. Da mesma forma, criou os fundamentos para a educação na área, a princípio, de pacientes e familiares, e mais tarde de profissionais, em especial os enfermeiros, desenvolvendo, assim, a especialidade estomaterapia ${ }^{1}$.

À medida que o interesse pelo cuidado de pessoas com estomia aumentou em todo o mundo, Norma moveu esforços para congregar representantes internacionais, de modo a criar uma identidade corporativa para aqueles que se preocupavam com a reabilitação de pessoas com estomias, compartilhando conhecimentos e discussões sobre o progresso da especialidade e dos programas de educação. Assim, foi criado o World Council of Enterostomal Therapy Conselho Mundial de Estomaterapia (WCET)2, que em 1980 definiu que a estomaterapia é uma especialidade exclusiva do enfermeiro.

Ela trabalhou incansavelmente para difundir a ideia de que todas as pessoas com estomia, independentemente de onde vivem, possam ser atendidas por um enfermeiro estomaterapeuta, de modo a garantir-lhes uma vida plena.

1. Universidade de Pernambuco - Faculdade de Enfermagem Nossa Senhora das Graças - Recife (PE), Brasil.

2. Universidade de Taubaté - Departamento de Enfermagem e Nutrição e Programa de Mestrado em Desenvolvimento Humano - Taubaté (SP), Brasil.

*Autora correspondente: isabel.santos@upe.br

Como citar: Santos ICRV, Paula MAB. Seguindo os passos de Norma Gill. ESTIMA, Braz. J. Enterostomal Ther., 2021, 19 : e1421.

https://doi.org/10.30886/estima.v19.1003_PT 
É impossível, em um editorial, descrever a dimensão dos feitos dessa mulher em prol da especialidade e, principalmente, das pessoas com estomias. Muitos ainda devem argumentar que os desafios por ela enfrentados não existem mais ou não são mais os mesmos. De fato, o desenvolvimento social com a distribuição desigual de renda, ocupação territorial desordenada, a transição epidemiológica e a dificuldade de acesso aos serviços de saúde, impõem aos enfermeiros estomaterapeutas novos desafios. Vivemos em um país em que as estatísticas são ineficientes e, por isso, não sabemos até hoje o quantitativo exato de pessoas com estomias no Brasil. Da mesma forma, sabe-se que muitos pacientes com ileostomias e colostomias temporárias têm dificuldade de acesso às cirurgias de reversão.

Muitas pessoas com estomias apresentam problemas, inclusive, para cuidados básicos, e possíveis complicações podem ocorrer, como a irritação da pele periestomia e dificuldades relacionadas ao uso e acesso ao equipamento coletor ${ }^{3}$,e isso reveste-se de importância quando se associa ao quantitativo e tipo de equipamentos fornecidos, por lei, às pessoas com estomia e ao baixo poder aquisitivo da população acometida, além das condições de moradia, muitas vezes precárias, incluindo a falta de saneamento básico e a distância dos serviços de atenção primária à saúde.

Ninguém nunca disse que seguir os passos da pioneira Norma Gill seria uma tarefa fácil! E é isso que reflete a magnitude de nossa especialidade enquanto profissionais especialistas, uma vez que somos preparados, também, para identificar as diferentes necessidades de cada fase da vida das pessoas que cuidamos, e podermos criar novas oportunidades para que tenham uma vida produtiva e plena.

Ao enfrentar os desafios, devemos nos manter atentos e continuarmos, como Norma, atestando nossa competência clínica por meio do conhecimento científico, usando estratégias educacionais, inclusive, por meio da tecnologia da informação, que nos permite chegar a locais que muitas vezes não podem ser alcançados fisicamente. Não podemos nos deixar abater por dificuldades, mas antes disso, analisá-las, buscando conhecimentos ou até criando evidências para melhorar a prática clínica, e, além de tudo isso, é mais que necessário que estejamos juntos às pessoas com estomias, na busca por seus direitos e contribuindo, assim, para a efetivação de mudanças nos modelos assistenciais e nas políticas públicas.

Nessa luta, não estamos sozinhos, temos ao nosso dispor a Associação Brasileira de Estomaterapia: estomias, feridas e incontinências (SOBEST), que, como um braço do WCET, nos reúne, nos capacita/atualiza, direciona e nos distingue.

Que no dia 26 de junho, possamos relembrar de onde viemos, acendendo a chama em homenagem a essa mulher memorável e nos perguntando: estamos fazendo a diferença na vida das pessoas que demandam cuidados especializados em estomaterapia? Estamos seguindo os passos de Norma Gill?

\section{REFERENNCIAS}

1. Murphree RW, Ayello EA. Honoring the 100th birthday of Norma N. Gill, founder of Enterostomal Therapy. Adv Skin Wound Care. 2020;33(6):288-9. https://doi.org/10.1097/01.ASW.0000661784.40598.52

2. Stelton S. The WCET at 40. Adv Skin Wound Care. 2018;31(4):150-1. https://doi.org/10.1097/01.ASW.0000531296.56431.c1

3. Hendren S, Hammond K, Glasgow SC, Perry WB, Buie WD, Steele SR et al. Clinical Practice Guidelines for Ostomy Surgery. Dis Colon Rectum 2015;58(4):375-87. https://doi.org/10.1097/DCR.0000000000000347 